\title{
Pengaruh Kualitas Pelayanan Jasa Terhadap Kepuasan Pelanggan Pada Toko Emas Gajah, Batu
}

\author{
Alfiah \\ Program Studi Manajemen \\ Sekolah Tinggi Ilmu Ekonomi Kertanegara Malang \\ alfiah.said@gmail.com
}

\begin{abstract}
Toko Emas Gajah is the best gold shop located in Batu City that provides the best after-sales and maintenance services for gold jewelry, and always provides the latest jewelry models. This study aims to explain the effect of service quality on customer satisfaction at TokoEmas Gajah. The measurement of the quality dimension uses five dimensions of service quality which consist of tangibles, reliability, responsiveness, assurance, and empathy dimensions. The research instrument used was a questionnaire distributed to 99 customers of Toko Emas Gajah which was taken using purposive sampling technique. Furthermore, the collected data was analyzed using multiple regression analysis to see the dimensions of service quality that were the most dominant influence on customer satisfaction at TokoEmas Gajah.The results of this study indicate the five variables of customer satisfaction simultaneously and partially have a significant effect on customer satisfaction at TokoEmas Gajah. While the factors that predominantly influence customer satisfaction in this gold shop are Reliability or reliability and are followed by variables of assurance, responsiveness and reliability
\end{abstract}

\section{Keywords: Service Quality, Customer Satisfaction, Gold Shop}

Abstraksi : CV. Toko Emas Gajah adalah toko emas terbaik yang berada di Kota Batu yang memberikan layanan purna jual-beli dan perawatan perhiasan emas terbaik, serta selalu memberikan model-model perhiasan yang selalu terbaru. Penelitian ini bertujuan untuk menjelaskan pengaruh kualitas layanan terhadap kepuasan pelanggan di Toko Emas Gajah. Pengukuran dimensi kualitas menggunakan lima dimensi kualitas layanan yang terdiri atas dimensi tangibles, reliability, responsiveness, assurance, dan empathy. Instrumen penelitian yang digunakan adalah kuesioner yang disebarkan kepada 99 orang pelanggan Toko Emas Gajah yang diambildengan menggunakan teknik purpossive sampling. Selanjutnya, data yang telah terkumpul dianilisis menggunakan analisis regresi berganda untuk melihat dimensi kualitas layanan yang paling dominan pengaruhnya terhadap kepuasan pelanggan Toko Emas Gajah. Hasil dari penelitian ini menunjukkan kelima variabel kepuasan pelanggan secara simultan dan parsial berpengaruh signifikan terhadap kepuasan pelanggan di Toko Emas GajahBatu. Sedangkan faktor yang berpengaruh dominan terhadap kepuasan pelanggan di toko emas ini adalah Reliability atau kehandalan dan diikuti oleh variabel assurance, responsiveness dan reliability.

Kata kunci: Kualitas Pelayanan, Kepuasan Pelanggan, Toko Emas

\section{Pendahuluan}

Dewasa ini semakin disadari bahwa kualitas pelayanan jasa dan kepuasan pelanggan merupakan faktor yang paling penting untuk bertahan dalam bisnis dan memenangkan persaingan. kualitas adalah suatu kondisi dinamis yang berhubungan dengan produk, jasa, manusia, proses, dan lingkungan yang memenuhi atau melebihi harapan. Kualitas pelayanan jasa yaitu upaya pemenuhan kebutuhan dan keinginan 
pelanggan serta ketepatan penyampaiannya untuk mengimbangi harapan pelanggan (Tjiptono,2006). Sedangkan Kepuasan pelanggan menurut Kotler dalam Arief (2007:167) adalah tingkat perasaan seseorang setelah membandingkan dengan kinerja yang ia rasakan atau alami terhadap harapannya.

Peningkatan kualitas merupakan salah satu strategi pemasaran yang ditekankan pada pemenuhan keinginan pelanggan. Untuk menciptakan layanan kualitas yang tinggi, sebuah perusahaan/lembaga harus menawarkan layanan yang mampu diterima atau dirasakan pelanggan sesuai dengan atau melebihi apa yang diharapkan pelanggan. Semakin tinggi kualitas pelayanan yang dirasakan dibanding harapannya, pelanggan tentu akan semakin puas.

Adhiyanto (2012) dalam jurnalnya yang berjudul Analisis Pengaruh Kualitas Pelayanan Terhadap Kepuasan Konsumen, lokasi penelitian adalah Balai Latihan Kerja Industri Semarang. Hasil yang di dapat yaitu pada dasarnya variabel bebas yang terdiri dari bukti fisik (tangible), kehandalan (reliability), daya tanggap (responsiveness), jaminan (assurance), empati (emphaty) semuanya berpengaruh positif dan signifikan terhadap kepuasan konsumen. Dengan pengaruh sebesar $68,5 \%$ sedangkan $31,5 \%$ lainnya dipengaruhi oleh variabel lain.

Syaiful Hurri (2009) dalam jurnalnya Pengaruh Kualitas Pelayanan Terhadap Keputusan Menginap Konsumen di Hotel Pelangi Batu. Hasil yang di dapat dari penelitian ini yaitu variabel bebas yang terdiri dari bukti fisik (tangible), kehandalan (reliability), daya tanggap (responsiveness), jaminan (assurance), empati (emphaty) berpengaruh positif terhadap keputusan menginap konsumen.

Hasil dari dua penelitian tersebut bahwa kualitas pelayanan atau variabel $\mathrm{X}$ yang terdiri dari bukti fisik (tangible), kehandalan (reliability), daya tanggap (responsiveness), jaminan (assurance), empati (emphaty) berpengaruh positif terhadap variabel $Y$ yaitu kepuasan konsumen dalam jurnalnya Adhiyanto dan keputusan menginap konsumen dalam jurnalnya Syaiful Hurri. Hal inilah yang menjadi salah satu alasan peneliti melakukan penelitian tentang kualitas pelayanan jasa di Toko Emas Gajah Batu.

\section{Metode}

Jenis data yang digunakan dalam penelitian ini adalah data primer dan data sekunder. Sedangkan teknik pengumpulan data yang dilakukan dalam penelitian ini adalah metode angket yang menggunakan skala likert dari 1-5 dan dokumentasi serta wawancara. Penelitian ini merupakan penelitian Explanatory Research dengan metode kuantitatif. Walaupun uraiannya mengandung deskripsi, tetapi sebagian peneliti fokusnya terletak pada penjelasan hubungan variabel. Penelitian yang menjadi variabel terikat (dependent variable) adalah kepuasan pelanggan pada TokoEmas Gajah Batu dan kemudian dirotasikan dengan (Y). Sedangkan variabel bebas (independent variable) adalah kualitas pelayanan jasa yang di rotasikan dengan $(X)$. Variabel kualitas pelayanan dibagi menjadi lima sub variabel, yaitu bukti fisik $\left(X_{1}\right)$, kehandalan $\left(X_{2}\right)$, daya tanggap $\left(X_{3}\right)$, jaminan $\left(X_{4}\right)$, dan empati $\left(X_{5}\right)$. Adapun gambaran mengenai hubungan antar variabel tersebut terlihat pada gambar 1. 


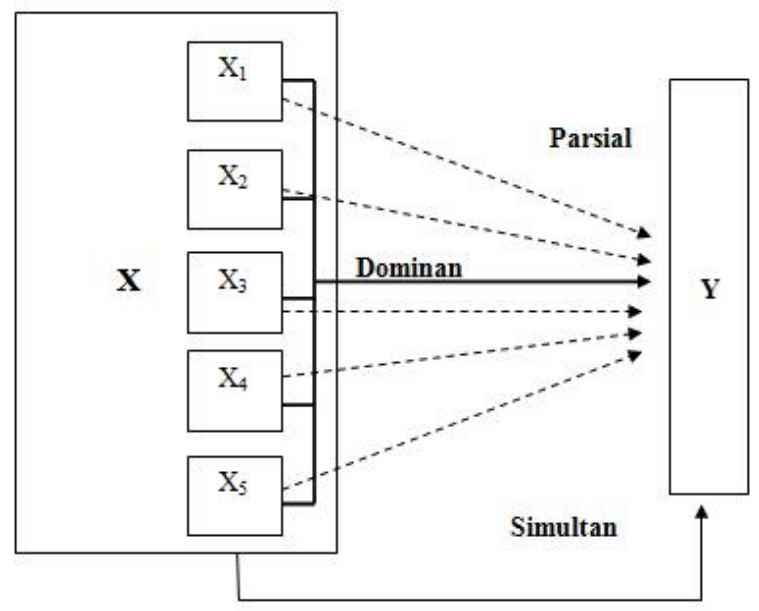

Gambar 1.

Skema Hubungan antara Variabel Independen dan Dependen

Keterangan :

$\mathbf{X}$ : Kualitas PelayananJasa

$\mathbf{X}_{1}$ : Bukti Fisik

$\mathbf{X}_{2}$ : Kehandalan

$\mathbf{X}_{\mathbf{3}}$ : Daya Tanggap

$\mathbf{X}_{\mathbf{4}}$ :Jaminan

$\mathbf{X}_{5}:$ Empati

$\mathbf{Y}$ : Kepuasan Pelanggan

Agar pembahasan penelitian ini lebih terarah maka penelitian dibatasi hanya pada variabel yang diteliti yaitu kualitas pelayanan Jasa yang meliputi lima dimensi yaitu bukti fisik, kehandalan, daya tanggap, jaminan, dan empati serta pengaruhnya terhadap kepuasan pelanggan pada Toko Emas Gajah Batu dengan jumlah populasi 9.180 orang pelanggan dan sampel sebanyak 99 orang.

\section{Hasil dan Pembahasan}

\section{A. Hasil Penelitian}

1. Uji Validitas

Uji validitas dilakukan dengan membandingkan nilai rhitung (untuk setiap butir pertanyaan dapat dilihat pada kolom corrected item-total correlations), dengan $r$ tabel dengan mencari degree off reedom $(d f)=\mathrm{N}-2$, dalam hal ini $\mathrm{N}$ adalah jumlah sampel. Jika $r$ hitung $>r$ tabeldan bernilai positif,maka pertanyaan (indikator) tersebut dikatakan valid (Ghozali, 2006:89). Bila dilihat dari $r$ tabel maka nilai $r$ tabel pada penelitian ini:

$$
d f=99-2=97
$$


Dalam pengujian ini penulis menentukan nilai signifikansi sebesar $5 \%(0,05)$. Maka besar $r$ tabel pada penelitian ini bila dilihat pada daftar $r$ tabel adalah 0,197. Pengujian Validitas selengkapnya dapat dilihat pada tabel 4.13 berikut ini:

Tabel 1. HasilPengujianValiditas

\begin{tabular}{|l|l|l|l|}
\hline Indikator & $r_{\text {hitung }}$ & $r_{\text {tabel }}$ & Ket. \\
\hline Bukti Fisik (X1) & & & \\
X1.1 & 0.264 & 0.197 & Valid \\
X1.2 & 0.478 & 0.197 & Valid \\
X1.3 & 0.428 & 0.197 & Valid \\
X1.4 & 0.591 & 0.197 & Valid \\
\hline Kehandalan (X2) & & & \\
X2.1 & 0.485 & 0.197 & Valid \\
X2.2 & 0.493 & 0.197 & Valid \\
X2.3 & 0.446 & 0.197 & Valid \\
X2.4 & 0.435 & 0.197 & Valid \\
\hline Daya Tanggap & & & \\
(X3) X3.1 & & & \\
X3.2 & 0.502 & 0.197 & Valid \\
X3.3 & 0.450 & 0.197 & Valid \\
X3.4 & 0.349 & 0.197 & Valid \\
& 0.439 & 0.197 & Valid \\
\hline Jaminan (X4) & & & \\
X4.1 & 0.357 & 0.197 & Valid \\
X4.2 & 0.595 & 0.197 & Valid \\
X4.3 & 0.451 & 0.197 & Valid \\
X4.4 & 0.519 & 0.197 & Valid \\
\hline Empati (X5) & 0.512 & 0.197 & Valid \\
X5.1 & 0.373 & 0.197 & Valid \\
X5.2 & 0.459 & 0.197 & Valid \\
X5.3 & 0.543 & 0.197 & Valid \\
X5.4 & & & \\
Kepuasan & & & \\
pelanggan (Y) & & 0.197 & Valid \\
Y1 & & 0.197 & Valid \\
Y2 & & & Valid \\
Y3 & & & \\
\hline
\end{tabular}

Sumber : data primer diolahpenulis, 2018- SPSS 17.0

Tabel 1 menunjukkan semua indikator yang digunakan untuk mengukur variabel-variabel yang digunakan dalam penelitian ini mempunyai nilai korelasi yang lebih besar dari 0,197. Dari hasil tersebut menunjukkan bahwa semua indikator tersebut adalah valid.

\section{Uji Reliabilitas}

Pengujian reliabilitas dalam penelitian ini adalah dengan menggunakan rumus Cronbach's Alpha. Hasil pengujian reliabilitas untuk masing-masing variabel yang diringkas pada tabel 1 sebagai berikut: 
Tabel 2. Hasil Uji Reliabilitas

\begin{tabular}{lcc}
\hline \multicolumn{1}{c}{ Variabel } & Alpha & Keterangan \\
\hline Bukti Fisik & 0.646 & Reliabel \\
Kehandalan & 0.674 & Reliabel \\
Daya Tanggap & 0.643 & Reliabel \\
Jaminan & 0.682 & Reliabel \\
Empati & 0.680 & Reliabel \\
Kepuasan pelanggan & 0.622 & Reliabel \\
\hline
\end{tabular}

Sumber : Data primer diolah penulis, 2018 -SPSS 17.0

Hasil uji reliabilitas tersebut menunjukkan bahwa semua variabel mempunyai koefisien Alpa yang cukup besar yaitu diatas 0.600 sehingga dapat dikatakan semua konsep pengukur masing-masing variabel dari kuesioner adalah reliabel yang berarti bahwa kuesioner yang digunakan dalam penelitian ini merupakan kuesioner yang handal.

\section{Uji Normalitas}

Pengujian dilakukan dengan menggunakan grafik P-P Plot. Data yang normal adalah data yang membentuk titik-titik yang menyebar tidak jauh dari garis diagonal. Hasil analisis regresi linier dengan grafik normal P-P Plot terhadap residual error model regresi diperoleh sudah menunjukkan adanya pola grafik yang normal, yaitu adanya sebaran titik yang berada tidak jauh dari garis diagonal.

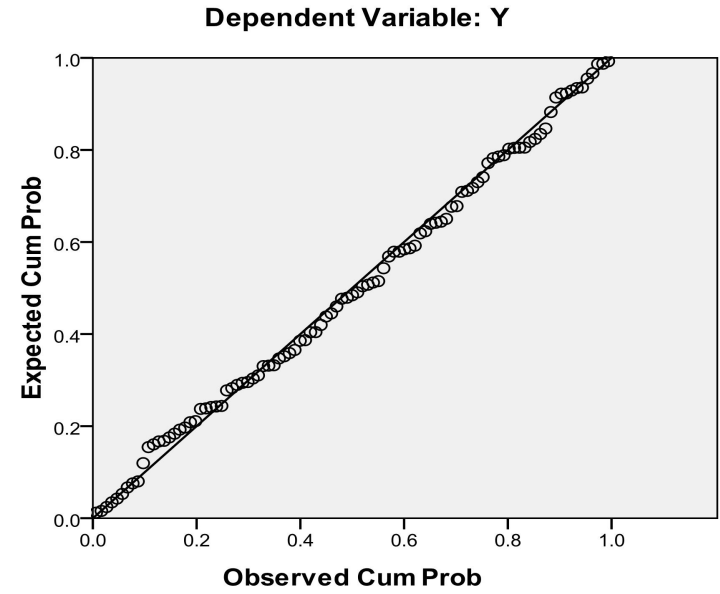

Gambar 2.

Grafik Hasil Uji Normalitas

Hasil pengujian tersebut menunjukkan bahwa titik-titik berada tidak jauh dari garis diagonal. Hal ini berarti bahwa model regresi tersebut sudah berdistribusi normal. 


\section{Uji Multikolonieritas}

Tabel 3. Pengujian Multikolonieritas

\begin{tabular}{lcl}
\hline \multicolumn{1}{c}{ Variabel } & VIF & \multicolumn{1}{c}{ Keterangan } \\
\hline Bukti Fisik (X1) & 2.633 & $\begin{array}{l}\text { Tidak terdapat } \\
\text { Multikolonieritas }\end{array}$ \\
$\begin{array}{l}\text { Kehandalan } \\
\text { (X2) }\end{array}$ & 2.555 & $\begin{array}{l}\text { Tidak terdapat } \\
\text { Multikolonieritas }\end{array}$ \\
$\begin{array}{l}\text { Daya Tanggap } \\
\text { (X3) }\end{array}$ & 4.448 & $\begin{array}{l}\text { Tidak terdapat } \\
\text { Multikolonieritas }\end{array}$ \\
Jaminan (X4) & 2.695 & $\begin{array}{l}\text { Tidak terdapat } \\
\text { Multikolonieritas } \\
\text { Tidak terdapat } \\
\text { Multikolonieritas }\end{array}$ \\
\hline
\end{tabular}

Sumber :Data primer diolahpenulis, 2018 -SPSS 17.0

Hasil pengujianmenunjukkan bahwa nilai VIF dari semua variabel bebas memiliki nilai yang lebih kecil dari 10 . Hal ini berarti variabel-variabel penelitian tidak menunjukkan adanya gejala multikolonieritas dalam model regresi.

\section{Uji Heteroskedastisitas}

Uji ini bertujuan untuk menguji apakah dalam model regresi terjadi ketidaksamaan varian residual antara yang satu dengan yang lain. Jika varian residual dari suatu pengamatan kepengamatan yang lain tetap, maka disebut homokedastisitas. Dan jika varians berbeda, disebut heteroskedastisitas.

Untuk mengetahui ada tidaknya gejala heteroskedastisitas dapat dilakukan dengan menggunakan grafik heteroskedastisitas antara nilai prediksi variabel dependen dengan variabel independen. Dari scatteplots dibawah ini terlihat titik-titik menyebar secara acak serta tersebar baik diatas maupun dibawah dengan angka 0 dan sumbu $Y$, hal ini dapat disimpulkan bahwa tidak terjadi heteroskedastisitas pada model regresi, sehingga model regresi layak untuk digunakan dalam melakukan pengujian. Untuk lebih jelasnya dapat dilihat pada gambar 3 berikut ini.

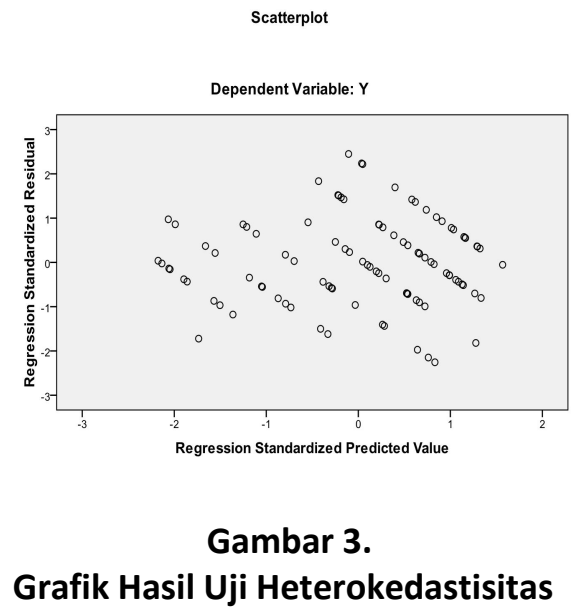




\section{Uji Regrasi Linier}

Uji ini bertujuan untuk menguji apakah variabel independen dalam model regresi memiliki pengaruh terhadap variabel dependen. Untuk mengetahui ada tidaknya pengaruh secara simultan kita bisa melihatnya dari nilai $\mathrm{F}$ dengan membandingkan antara $\mathrm{F}$ tabel dan $\mathrm{F}$ hitung, sedangkan Untuk mengetahui ada tidaknya pengaruh secara parsial kita bisa melihatnya dari nilai t dengan membandingkan antara $t$ tabel dan $t$ hitung Hasil analisis regresi menunjukkan bahwa secara simultan keseluruhan variabel independen berpengaruh terhadap variabel dependen. Sedangkan secara parsial terdapat dua variabel dependen yang memiliki nilai signifikansi di bawah 0.05 dan nilai thitung lebih kecil daripada nilai $t$ tabel. Variabel yang tidak signifikan adalah bukti fisik dan empati.

Tabel 3. Hasil Analisis Regresi Linier Berganda

\begin{tabular}{|l|c|c|c|c|}
\hline \multicolumn{1}{|c|}{ Variabel Bebas } & $\begin{array}{c}\text { Koefisien } \\
\text { Regresi }\end{array}$ & $\boldsymbol{\beta}$ & thitung & Sig \\
\hline Bukti Fisik $\left(\mathrm{X}_{1}\right)$ & -0.143 & -0.152 & -1.656 & 0.101 \\
\hline Kehandalan $\left(\mathrm{X}_{2}\right)$ & 0.423 & 0.517 & 5.716 & 0.000 \\
\hline Daya Tanggap $\left(\mathrm{X}_{3}\right)$ & 0.438 & 0.485 & 4.064 & 0.000 \\
\hline Jaminan $\left(\mathrm{X}_{4}\right)$ & 0.253 & 0.301 & 3.241 & 0.002 \\
\hline Empati $\left(\mathrm{X}_{5}\right)$ & -0.263 & -0.311 & -2.796 & 0.160 \\
\hline Konstanta & $: 0.617$ & & \\
Std Error & $: 0.981$ & & \\
Adj.R square & $: 0.686$ & & \\
Fhitung & $: 43.755$ & & \\
Sig F & $: 0.000$ & & \\
SEE & $: 0.909$ & & \\
\hline
\end{tabular}

Sumber :Data primer diolah penulis, 2018 - SPSS 17.0

\section{B. PEMBAHASAN}

\section{Pengaruh Bukti Fisik Terhadap Kepuasan pelanggan}

Dalam penelitian ini menunjukkan bahwa bukti fisik tidak selalu berpengaruh terhadap kepuasan pelanggan. Tidak adanya pengaruh yang signifikan dari bukti fisik (tangible) ini nampaknya dikarenakan pelanggan kurang memperhatikan kondisi fisik fasilitas yang diberikan, karena pelanggan menganggap yang terpenting adalah pelayanan atau service yang baik. Berdasarkan tinjauan deskripsi jawaban responden pada tabel 3 diperoleh bahwa penilaian kuesioner terhadap bukti fisik (tangible) cukup sedangkan penilaian terhadap kepuasan pelanggan relatif tinggi, sehingga dimungkinkan ada variabel lain selain bukti fisik (tangible) yang mempengaruhi kepuasan pelanggan. Dengan demikian $\mathrm{H}_{2}\left(\mathrm{H}_{\mathrm{a}}\right)$ ditolak karena variabel bukti fisik (tangible) secara parsial tidak berpengaruh signifikan terhadap kepuasan pelanggan. 


\section{Pengaruh Kehandalan Terhadap Kepuasan pelanggan}

Berdasarkan tinjauan deskripsi jawaban responden pada tabel 3 diperoleh bahwa penilaian kuesioner terhadap kehandalan (reliability) bernilai cukup sedangkan penilaian terhadap kepuasan pelanggan relatif tinggi, sehingga dimungkinkan ada variabel lain selain kehandalan (reliability) yang mempengaruhi kepuasan pelanggan. Dengan demikian dapat disimpulkan bahwa $\mathrm{H}_{3}\left(\mathrm{H}_{a}\right)$ diterima karena variabel kehandalan (reliability) berpengaruh positif dan signifikan terhadap kepuasan pelanggan.

\section{Pengaruh Daya Tanggap terhadap Kepuasan Pelanggan}

Hasil dari uji hipotesis dalam penelitian ini menunjukkan bahwa daya tanggap (responsiveness) berpengaruh positif dan signifikan terhadap kepuasan pelanggan. Berdasarkan tinjauan deskripsi jawaban responden pada tabel 3 diperoleh bahwa penilaian kuesioner terhadap daya tanggap (responsiveness) bernilai cukup sedangkan penilaian terhadap kepuasan pelanggan relatif tinggi, sehingga dimungkinkan ada variabel lain selain dayatanggap (responsiveness) yang mempengaruhi kepuasan pelanggan. Dengan demikian dapat disimpulkan bahwa $\mathrm{H}_{4}$ $\left(H_{a}\right)$ diterima karena variabel dayatanggap (responsiveness) berpengaruh positif dan signifikan terhadap kepuasan pelanggan.

\section{Pengaruh Jaminan Terhadap Kepuasan pelanggan}

Hasil dari ujihi potesis dalam penelitian ini menunjukkan bahwa jaminan (assurance) berpengaruh positif dan signifikan terhadap kepuasan pelanggan. Berdasarkan tinjauan deskripsi jawaban responden pada tabel 3 diperoleh bahwa penilaian kuesioner terhadap jaminan (assurance) bernilai cukup sedangkan penilaian terhadap kepuasan pelanggan relatif tinggi, sehingga dimungkinkan ada variabel lain selain jaminan (assurance) yang mempengaruhi kepuasan pelanggan. Dengan demikian dapat disimpulkan bahwa $\mathrm{H}_{5}\left(\mathrm{H}_{\mathrm{a}}\right)$ diterima karena variabel jaminan (assurance) berpengaruh positif dan signifikanterhadapkepuasanpelanggan.

\section{Pengaruh Empati Terhadap Kepuasan pelanggan}

Hasil dari uji hipotesis dalam penelitian ini menunjukkan bahwa empati (emphaty) tidak berpengaruh signifikan terhadap kepuasan pelanggan. Berdasarkan tinjauan deskripsi jawaban responden pada tabel 3 diperoleh bahwa penilaian kuesioner terhadap empati (emphaty) cukup sedangkan penilaian terhadap kepuasan pelanggan relatif tinggi, sehingga dimungkinkan ada variabel lain selain empati (emphaty) yang mempengaruhi kepuasan pelanggan. Dengan demikian $\mathrm{H}_{6}\left(\mathrm{H}_{\mathrm{a}}\right)$ ditolak karena variabel empati (emphaty) secara parsial tidak berpengaruh signifikanterhadapkepuasanpelanggan. 


\section{Pengaruh Kualitas Pelayanan Jasa Secara Simultan Terhadap Kepuasan pelanggan}

Berdasarkan hasil uji hipotesis tabel 3 terbukti ada pengaruh bukti fisik $\left(X_{1}\right)$, kehandalan $\left(X_{2}\right)$, daya tanggap $\left(X_{3}\right)$, jaminan $\left(X_{4}\right)$, dan empati $\left(X_{5}\right)$ secara bersamasama terhadap kepuasan pelanggan pada CV TOKO EMAS GAJAH. Hal ini membuktikan bahwa kualitas pelayanan jasa baik bukti fisik maupun nonfisik mempunyai nilai tersendiri dimata pelanggan. Sehingga dapat dikatakan bahwa kualitas pelayanan jasa masih efektif dijadikan sumber keberhasilan pelayanan yang berorientasi untuk menciptakan kepuasan pelanggannya. Dengan demikian $\mathrm{H}_{1}\left(\mathrm{H}_{\mathrm{a}}\right)$ diterima karena variabel kualitas pelayanan jasa yang terdiri dari bukti fisik $\left(X_{1}\right)$, kehandalan $\left(X_{2}\right)$, daya tanggap $\left(X_{3}\right)$, jaminan $\left(X_{4}\right)$,dan empati $\left(X_{5}\right)$ secara bersamasama berpengaruh positif dan signifikan terhadap kepuasan pelanggan.

\section{Kualitas Pelayanan Jasa Yang Berpengaruh Dominan Terhadap Kepuasan pelanggan}

Berdasarkan hasil uji t yang dilakukan sebelumnya maka dapat disimpulkan nilai standardized beta tertinggi ditunjukkan oleh variabel kehandalan (reliability). Selain itu pada hasil analisis deskriptif pada tabel 3 kehandalan dipersepsikan paling baik oleh pelanggan dengan adanya temuan nilai indeks yang tinggi. Sehingga variabel kehandalan (reliability) dinyatakan sebagai variabel dominan yang berpengaruh terhadap kepuasan pelanggan.

Hal ini sesuai dengan pendapat Lupiyoadi dan Hamdani (2006), bahwa kehandalan (reliability) adalah kemampuan untuk memberikan pelayanan sesuai dengan apa yang dijanjikan secara akurat dan terpercaya. Kinerja harus sesuai dengan harapan pelanggan karena pemenuhan janji dalam pelayanan akan mencerminkan kredibilitas perusahaan. Semakin baik persepsi pelanggan terhadap kehandalan perusahaan maka kepuasan pelanggan juga akan semakin tinggi. Dan jika persepsi pelanggan terhadap kehandalan buruk maka kepuasan pelanggan juga akan semakin rendah.

\section{KESIMPULAN}

Kesimpulan yang dapat diambil pada penelitian dengan judul Pengaruh Kualitas Pelayanan Jasa Terhadap Kepuasan Pelanggan pada CV TokoEmas Gajah Batuadalah:

1. Hasil penelitian menunjukkan bahwa kualitas pelayanan Jasa yang terdiri dari bukti fisik $\left(X_{1}\right)$, kehandalan $\left(X_{2}\right)$, daya tanggap $\left(X_{3}\right)$, jaminan $\left(X_{4}\right)$, dan empati $\left(X_{5}\right)$ secara simultan berpengaruh positif dan signifikan terhadap kepuasan pelanggan.

2. Hasil penelitian menunjukkan bahwa variabel bukti fisik (tangible) secara parsial tidak berpengaruh terhadap kepuasan pelanggan. Sehingga dugaan sementara yang mengatakan bahwa bukti fisik mempunyai pengaruh secara parsial terhadap kepuasan pelanggan bernilai salah. 
3. Hasil penelitian menunjukkan bahwa variabel kehandalan (reliability) secara parsial berpengaruh terhadap kepuasan pelanggan. Sehingga dugaan sementara yang mengatakan bahwa kehandalan mempunyai pengaruh secara parsial terhadap kepuasan pelanggan bernilai benar.

4. Hasil penelitian menunjukkan bahwa variabel daya tanggap (responsiveness) secara parsial berpengaruh terhadap kepuasan pelanggan. Sehingga dugaan sementara yang mengatakan bahwa daya tanggap mempunyai pengaruh secara parsial terhadap kepuasan pelanggan bernilai benar.

5. Hasil penelitian menunjukkan bahwa variabel jaminan (assurance) secara parsial berpengaruh terhadap kepuasan pelanggan. Sehingga dugaan sementara yang mengatakan bahwa jaminan mempunyai pengaruh secara parsial terhadap kepuasan pelanggan bernilai benar.

6. Hasil penelitian menunjukkan bahwa variabel empati (emphaty) secara parsial tidak berpengaruh terhadap kepuasan pelanggan. Sehingga dugaan sementara yang mengatakan bahwa empati mempunyai pengaruh secara parsial terhadap kepuasan pelanggan bernilai salah.

7. Variabel kehandalan (reliability) memiliki pengaruh dominan terhadap kepuasan pelanggan. Hal ini dapat diartikan bahwa karyawan telah melakukan pelayanan pada dimensi kehandalan (reliability) dengan keakuratan yang tinggi, sehingga mampu menciptakan persepsi yang baik dibenak pelanggan yang membuat pelanggan merasa puas.

\section{DAFTAR PUSTAKA}

Abdullah, T., \&Tantri, F. (2012). Manajemen Pemasaran. Jakarta: Raja Grafindo Persada.

Arikunto, Suharsimi. 2006. Prosedur Penelitian Suatu Pendekatan Praktik. Jakarta :Rineka Cipta

Atmaja, H.S. 2003.Pengaruh Kualitas Jasa Terhadap Kepuasan Pelanggan Dalam Membangun Loyalitas Pelanggan (StudiKasus Pelanggan Multimedia Akses PT Telkom). Tesis Fakultas Ekonomi Universitas Indonesia, tidak diterbitkan.

Cahyadi, Eko. 2003. KualitasPelayanan, Kepuasan dan Loyalitas Pelanggan Pada Industri Perbankan Islam Dengan Menggunakan Metode CARTER (Kasus Bank Mualamat Indonesia Cabang Rawamangun). Skripsi Fakultas IImu Sosial dan Ilmu Politik Universitas Indonesia, tidak diterbitkan.

Caruana, A. 2002.Service Loyalty The Effects of Service Quality and The Mediating Role of Customer Satisfaction. European Journal of Marketing, 36.

Cooper, D.R., \& Schindler, P.S. 2006.Business Research Methods (9th ed.). New York: McGrawHill/Irwin. Elu, Balthasar. 2005. Manajemen Penanganan Komplain Konsumen di Industri Jasa. Jurnal Imu Administrasi dan Organisasi, Bisnis \& Birokrasi, Vol. 13, No. 3 (September). 
Gilbert, G.R. et.al. 2004. Measuring Customer Satisfaction in The Fast Food Industry: A crossnational Approach. The Journal of Services Marketing, 18.

Kelana, S. J. (2012). Pengaruh Kualitas Pelayanan Terhadap Kepuasan Pelanggan di Sari Ater Hotel dan Resorts. Skripsi Fakultas Ekonomi dan Bisnis, Universitas Telkom.

Kotler, Philip. 2003. Marketing insights from A to Z. New York: John Wiley \& Sons, Inc.

Lestari, E. 2009.Menyimak Kepuasan Pelanggan di Mancanegara. www.swa.co.id. 5 Oktober. Lupiyoadi, R \&Hamdani, A. 2006.ManajemenPemasaranJasa. Jakarta: SalembaEmpat.

Lupiyoadi, R \&Hamdani, A. 2006.Manajemen PemasaranJasa. Jakarta: SalembaEmpat.

Malhotra, N.K. 2004.Marketing Research: An Applied Orientation.4th Edition. New Jersey: Pearson Education Inc.

Sugiyono. 2004. MetodePenelitianBisnis. Alfabeta, CV. Bandung

Wang, I., \&Shieh, C. (2006). The relationship between service quality and customer satisfaction: the example of CJCU library, Journal of Information \& Optimization Sciences, 27(1), 194-209.

Yuliarmi, N. N., \&Riyasa, P. (2007). Analisisfaktor-faktor yang mempengaruhi kepuasan pelanggan terhadap pelayanan PDAM kota Denpasar. Buletin Studi Ekonomi, 12(1), 928.

Zeithaml, ValarieA., Mary Jo Bitnerdan Dwayne D. Gremler. 2009. Services Marketing Integrating Customer Focus Across The Firm 5th Edition. McGraw-Hill : New York 